\title{
Verteporfin photodynamic therapy combined with intravitreal triamcinolone for choroidal neovascularization due to angioid streaks
}

This article was published in the following Dove Press journal:

Clinical Ophthalmology

27 May 2010

Number of times this article has been viewed

\author{
Alfredo Pece' \\ Gaetano Russo² \\ Federico Ricci ${ }^{3}$ \\ Vincenzo Isola' \\ Ugo Introini ${ }^{4}$ \\ Giuseppe Querques ${ }^{5}$ \\ 'Department of Ophthalmology, \\ Melegnano Hospital, Milan, Italy; \\ ${ }^{2}$ Fondazione Evangelica Betania, \\ Napoli, Italy; ${ }^{3}$ University of Tor \\ Vergata, Rome, Italy; ${ }^{5}$ University, \\ Paris XII, France; ${ }^{4}$ San Raffaele \\ University Hospital, Milan, Italy
}

Correspondence: Alfredo Pece, Department of Ophthalmology, Melegnano Hospital,Via Pandina I, 20077, Vizzolo Predabissi, Milan, Italy $\mathrm{Tel}+390298052267$

Fax +39022042262

Email pece.retina@mclink.it
Purpose: To report the visual outcome of photodynamic therapy (PDT) combined with intravitreal triamcinolone acetonide (IVTA) for choroidal neovascularization (CNV) secondary to angioid streaks (AS).

Methods: Five eyes of five consecutive patients (mean age $45 \pm 10$ years) with CNV secondary to AS were treated by combination of PDT and IVTA. TA $(4 \mathrm{mg} / 0.1 \mathrm{~mL})$ was injected 7 days before PDT.

Results: All patients completed the 12-month follow-up. CNV was subfoveal in three cases and extrafoveal in two. Median best-corrected visual acuity (BCVA) was 0.3 LogMAR (70 letters) at baseline (range 1.3-0.1), and 0.5 LogMAR (60 letters) at the final examination (range 1.0-0.1). At 12 months, one patient had severe visual deterioration, with a loss of seven lines of VA; Two patients lost up to three lines. One patient had no change in BCVA and the fifth gained nine lines of VA. Two patients received one further combination of PDT and IVTA after the first combination treatment. All eyes showed the CNV closure at the 12-month follow-up visit.

Conclusions: Combination of PDT and IVTA may reduce the need for retreatment and could be potentially useful for preserving vision in some patients with CNV due to AS.

Keywords: ocular corticosteroids

\section{Introduction}

Angioid streaks (AS) represent breaks in Bruch's membrane and are associated with various systemic diseases such as Ehlers-Danlos syndrome, Paget disease, and pseudoxanthoma elasticum (PXE). ${ }^{1}$ The main vision-threatening complication of AS is choroidal neovascularization (CNV) that develops in $72 \%$ to $86 \%$ of eyes. ${ }^{2,3}$ The natural history of CNV and its visual prognosis are poor with most eyes progressing to legal blindness. In addition, visual outcome after laser treatment or photodynamic therapy (PDT) with verteporfin is discouraging. ${ }^{1-5}$

PDT alone can occlude CNV, but tends to cause a transient inflammatory response and increase in capillary permeability along with an enhanced expression of vascular endothelial growth factor (VEGF) activity shortly after treatment that may limit its efficacy. The addition of intravitreal triamcinolone acetonide (IVTA), which, by reducing inflammation and inhibiting VEGF, ${ }^{6,7}$ seems to improve the visual outcomes in CNV secondary to age-related macular degeneration, may be useful even in the treatment of CNV secondary to AS. In this study we report the visual outcome of a series of patients with CNV secondary to AS treated by PDT combined with IVTA. 


\section{Methods}

We retrospectively analyzed five eyes of five consecutive patients (three men and two women; mean age $45 \pm 10$ years) with CNV due to AS, who underwent, at least 12 months before, $4 \mathrm{mg} / 0.1 \mathrm{~mL}$ IVTA injection followed, 1 week later, by standard PDT with verteporfin. Patients showing evidence of cutaneous PXE were included in this interventional study, if diagnosed with active $\mathrm{CNV}$ on fluorescein angiography (FA) examinations. Exclusion criteria included: 1) any other ocular diseases that could affect VA;2) presence of age-related macular degeneration; 3) previous treatment, such as laser photocoagulation, PDT, IVTA injection, or any anti-VEGF treatment within the past 3 months; 4 ) evidence of external ocular infection including blepharitis, conjunctivitis, or chalazion; 5) patients judged to be steroid responders. The patients signed a comprehensive consent form according to Good Clinical Practice guidelines, before proceeding with any examinations and treatments. All subjects underwent a complete ophthalmologic examination including fundus biomicroscopy, fluorescein angiography (FA) and best-corrected visual acuity (BCVA) before and 1 week, 1 month, then every 3 months after the combined therapy. BCVA was measured using standard Early Treatment of Diabetic Retinopathy Study (ETDRS) charts at 4 meters. Forced choice strategy was used to assess the BCVA threshold. The BCVA threshold was assigned when the patient was able to recognize four out of five characters per row. ${ }^{8}$ Optical coherence tomography (OCT 3000; Stratus, San Leandro, CA) was also performed at each visit. Retreatment decisions were made on the basis of: persistence or increase in leakage on FA frames, and/or persistence or increase in sub-retinal/intraretinal fluid on OCT scans, associated with a decrease of at least one ETDRS line of BCVA.

\section{Results}

Clinical details of patients and BCVA changes from baseline are summarized in Table 1. All CNV were actively leaking on FA, and were subfoveal in three cases, and juxtafoveal in the other two cases. Two eyes have been previously treated by PDT monotherapy at least 3 months before combination therapy. All patients completed the 12-month follow-up. Median BCVA was 0.3 LogMAR (70 letters) at baseline (range 1.3-0.1) and 0.5 LogMAR (60 letters) at the 12-month examination (range 1.0-0.1). Twelve months after the combination treatment, one patient showed severe visual deterioration, with a loss of seven ETDRS lines of visual acuity, and two patients lost up to lines. One patient had no change in BCVA and the fifth gained nine ETDRS lines. Two patients received one further combination of PDT

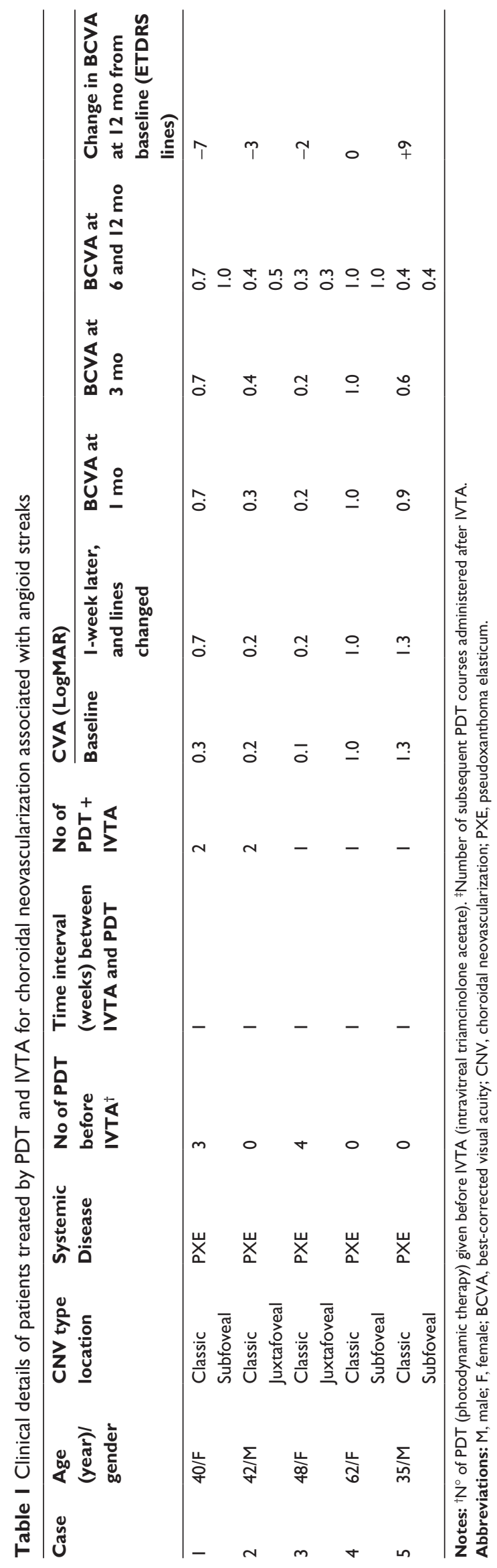


and IVTA injection after the first combination treatment (3 and 6 months, patient 1 and patient 2, respectively). All eyes showed the CNV closure at the 12-month follow-up visit, and no CNV enlargement as evaluated by FA and OCT (Figures 1-3). The two juxtafoveal CNV did not show subfoveal progression at the last follow-up. Mean OCT thickness was 320 micron at baseline and 250 micron at the 12-month follow-up visit. No side effects, such as uncontrolled intraocular pressure increase or cataract progression, were observed in any patient during follow-up. In all patients, fellow eyes did not develop active CNV during the study period.

\section{Discussion}

$\mathrm{CNV}$ is a serious complication of $\mathrm{AS}$, with a poor visual prognosis. The current literature offers no clues as to the effect of PDT combined with IVTA for CNV secondary to AS. Here we present the results of our retrospective analysis of consecutive eyes treated by PDT combined with IVTA for CNV secondary to AS. Some studies suggest that laser photocoagulation may offer limited benefits for extrafoveal $\mathrm{CNV}$, but probably does not change the long-term visual prognosis. ${ }^{4,5}$ For this reason we decided to include also the extrafoveal lesions, and not to treat them by laser photocoagulation.

In our series, at the 12-month follow-up visit, one patient experienced a severe visual loss, and two patients showed a moderate visual loss, due to scar development. One patient was stable (unchanged VA) and one patient showed an improvement in BCVA at 12 months. No correlation with previous PDT treatments, or CNV location, or BCVA at baseline was evident. Only two patients needed
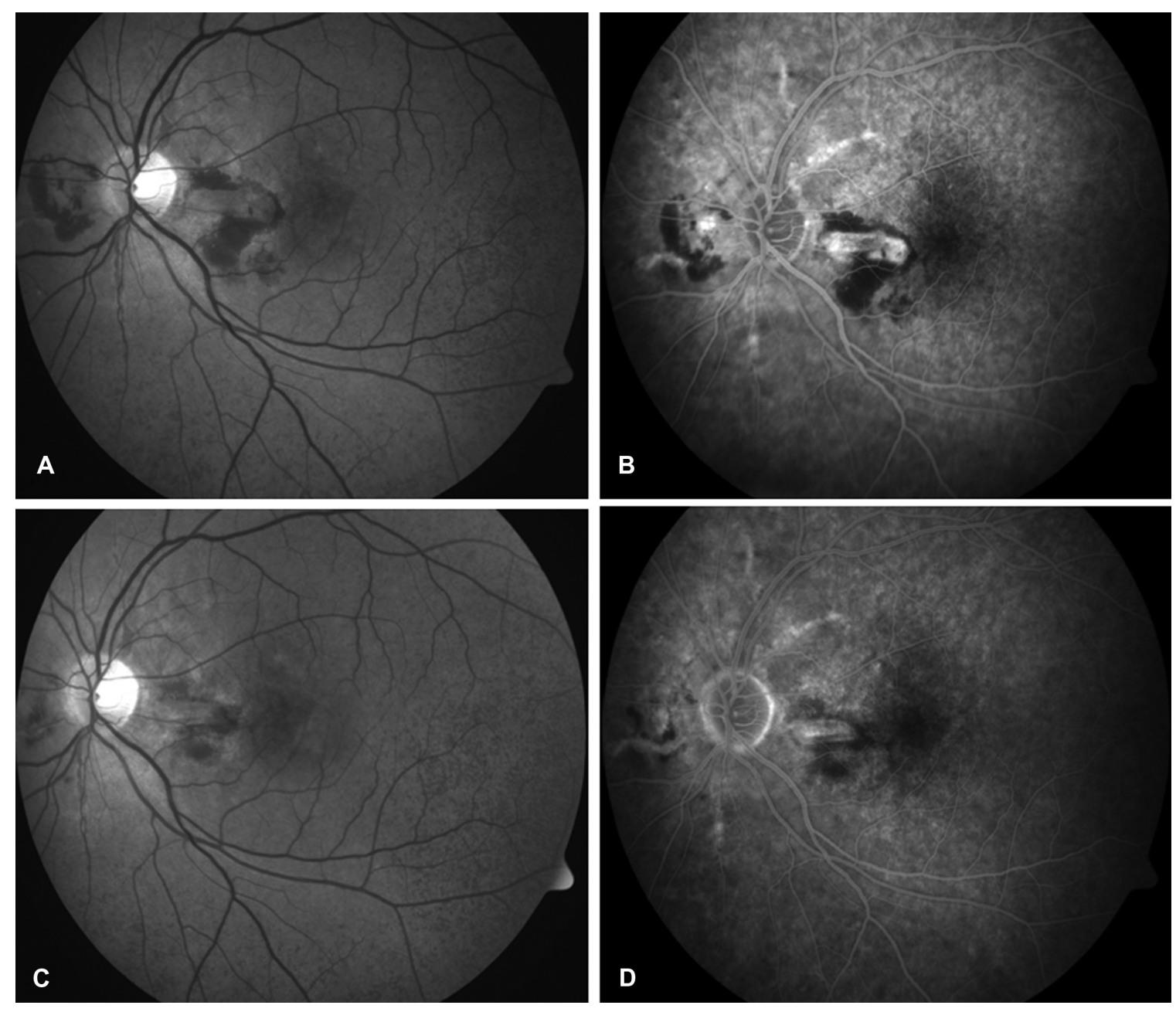

Figure I Left eye of patient 2. Black and white red-free photo A) shows peripapillary subretinal hemorrhages, and fluorescein angiography (FA) B) reveals the leakage from the neovascular complex (papillomacular region, and nasal to the optic disc), before receiving PDT/IVTA (best-corrected visual acuity 20/32 [0.2 LogMAR]). Twelve months after the Ist combined treatment (6 months after the 2nd combined treatment), best-corrected visual acuity was 20/63 (0.5 LogMAR), the red-free photo C) shows absorption of blood, and FA D) discloses a decrease in fluorescein leakage after regression of choroidal neovascularization.

Abbreviations: IVTA, intravitreal triamcinolone acetonide; PDT, photodynamic, therapy. 

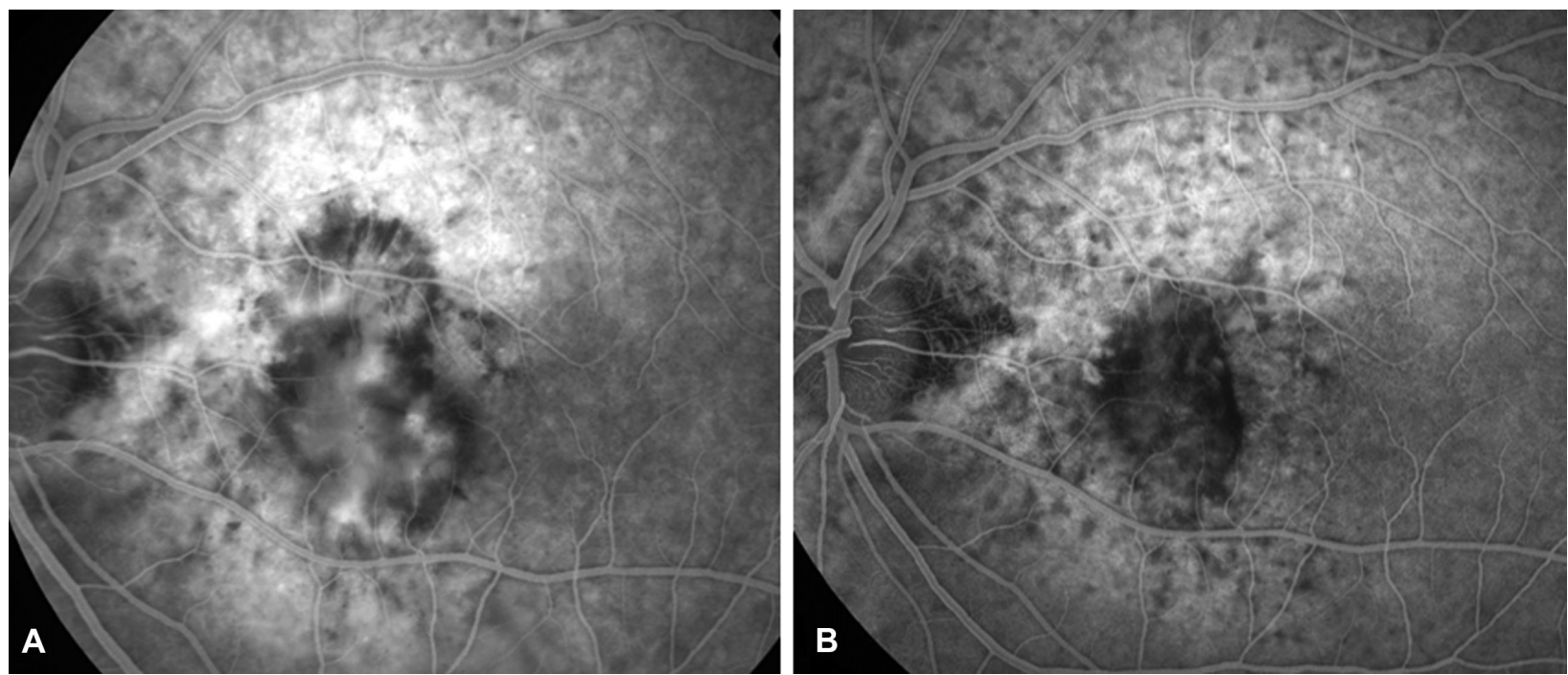

Figure 2 Left eye of patient 4. Fluorescein angiography A) before receiving PDT/IVTA (best-corrected visual acuity 20/200 [I LogMAR]). FA B) shows reduction of fluorescein leakage and decrease in size of choroidal neovascularization I year after PDT/IVTA. Best-corrected visual acuity was unchanged.

Abbreviations: IVTA, intravitreal triamcinolone acetonide; PDT, photodynamic, therapy.
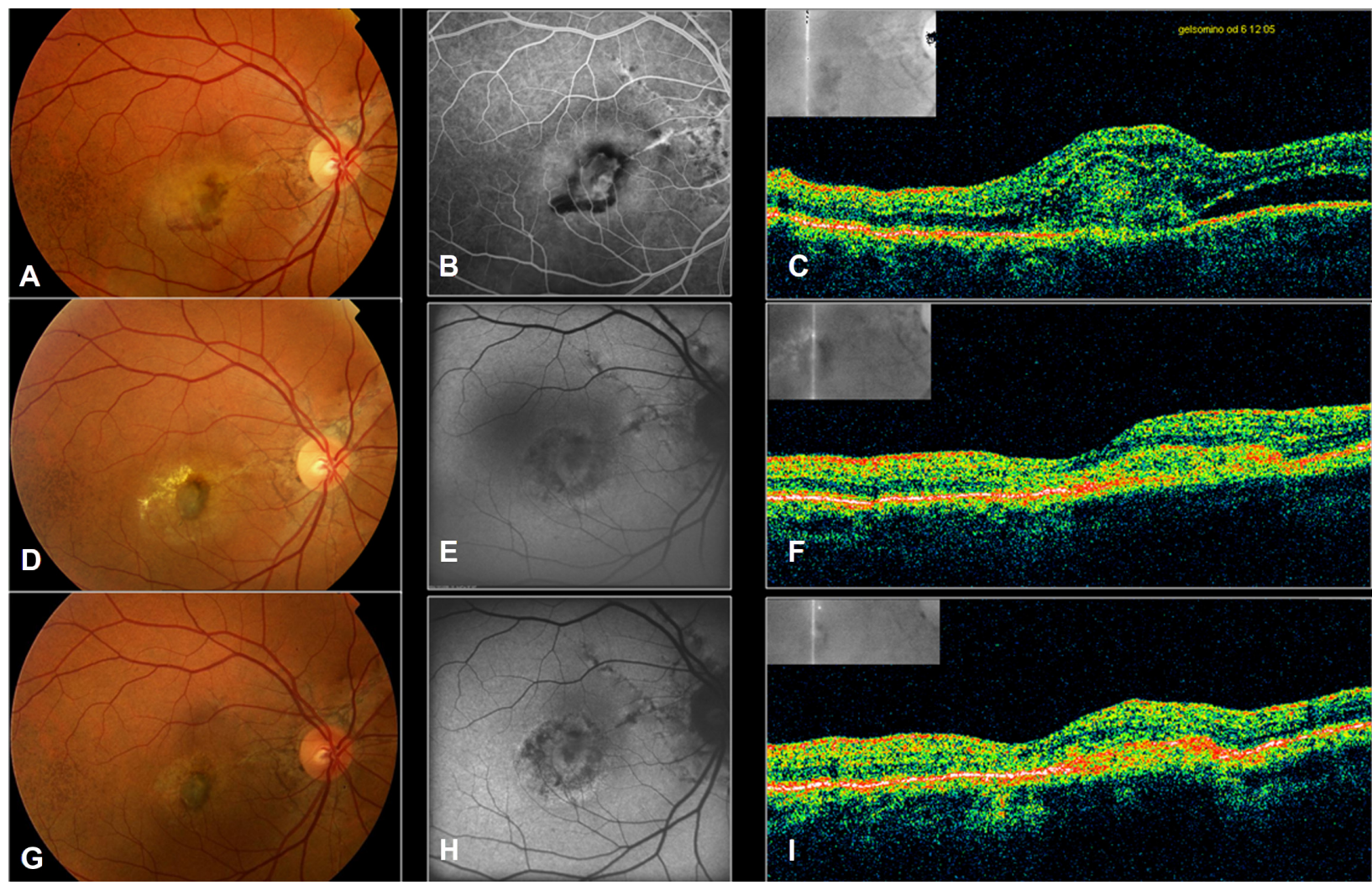

Figure 3 Right eye of patient 5. Color photo A) shows angioid streaks and subfoveal hemorrhages. Fluorescein angiography B) demonstrates the presence of choroidal neovascularization (CNV), and optical coherence tomography (OCT) C) reveals the neovascular complex as a high-reflective, red-yellow band in the subretinal space above the RPE/choriocapillaris layer, causing intra e subretinal exudation. Best-corrected visual acuity 20/400 [I.3 LogMAR]). Three months after PDT/IVTA: color photo D), fundus autofluorescence E), and OCT F) demonstrate restoration of foveal anatomy. Best-corrected visual acuity improved to 20/80 (0.6 LogMAR). One year after PDT/IVTA: color photo $\mathbf{G}$ ), fundus autofluorescence $\mathbf{H}$ ), and OCT I) show involution of CNV surrounded by some atrophic changes, and absence of blood and subretinal fluid. Best-corrected visual acuity was 20/50 (0.4 LogMAR).

Abbreviations: IVTA, intravitreal triamcinolone acetonide; RPE, retinal pigment epithelium; PDT, photodynamic, therapy. 
one more combined treatment over a 12-month follow-up period.

As reported in previous nonrandomized studies, IVTA reduces the frequency of PDT retreatment that could result from combining the short term effect of PDT-induced CNV closure with antiangiogenic and anti-inflammatory effects of intravitreal corticosteroids. ${ }^{6,7}$ Intravitreal triamcinolone acetonide is a corticosteroid with anti-inflammatory and antiangiogenic properties. ${ }^{9}$ IVTA monotherapy has shown a very limited beneficial effect for managing neovascular AMD.$^{10}$ However, IVTA in combination with PDT yielded favorable results by increasing VA, and lowering retreatment rate, in both pilot and randomized studies. ${ }^{11-13}$

In our series, IVTA was administered 7 days before PDT verteporfin therapy, to reduce intraretinal edema, thus increasing the photodynamic shutdown of CNV capillaries, and down-regulate PDT-mediated VEGF expression and inflammation. It is noteworthy that, in vitro studies have demonstrated that triamcinolone significantly reduced collagenase and proteoglycanase degrading activities, which was accompanied by inhibition of the expression of metalmatrix-proteinases (MMP) 1 and 3. ${ }^{14,15}$ Furthermore, PXE fibroblasts have been shown, in vitro, to exhibit increased proteolytic and elastolytic functions ${ }^{16,17}$ as well as MMP-2 activity ${ }^{18}$ that might lead to extracellular membrane degradation, Bruch membrane fragmentation and finally promote aggressive CNV formation. Therefore, it may be that, in such patients, IVTA would counteract not only the PDT side effects (choroidal ischemia, inflammation and VEGF upregulation), but also the increased proteolytic activity involved in CNV pathogenesis in PXE.

Although our study is limited by the small number of patients and short follow-up, our results suggest that PDT with IVTA may reduce the need for retreatment and could be potentially useful for preserving vision. Combination therapy may be able to arrest the disease progression with a single session, as recently proposed by Ahmadieh et al ${ }^{19}$ in AMD. However, side effects, even though not evident in this series, are well known and must always be taken into account. $^{7}$

In the era of promising new intravitreal anti-VEGF treatments for patients suffering from neovascular agerelated macular degeneration, it is interesting to observe that in small uncontrolled case series published in the literature, such treatments seem to stabilize VA in eyes with $\mathrm{CNV}$ secondary to AS. ${ }^{20-24}$ At the beginning of the current study, anti-VEGF were not yet available, and given that visual outcome after PDT with verteporfin alone were discouraging, ${ }^{5}$ we decided to investigate the effects of PDT combined with IVTA. Today, we would probably favor anti-VEGF injections over combined IVTA and PDT in the treatment of such patients. However, long-term follow-up and randomized controlled studies are needed to assess the safety and efficacy of both combined IVTA and PDT, and multiple intravitreous injections of anti-VEGF drugs for the treatment of choroidal neovascular membranes secondary to AS.

\section{Acknowledgment/disclosure}

The authors have no proprietary or commercial interest in any material discussed in this article. This study was supported by the Fondazione Retina 3000-Milano.

\section{References}

1. Mansour AM, Shields JA, Annesley WH Jr, et al. Macular degeneration in angioid streaks. Ophthalmologica. 1988;197:36-41.

2. Clarkson JG, Altman RD. Angioid streaks. Surv Ophthalmol. 1982;26:235-246.

3. Singerman LJ, Hatem G. Laser treatment of choroidal neovascular membranes in angioid streaks. Retina. 1981;1:75-83.

4. Pece A, Avanza P, Galli L, Brancato R. Laser photocoagulation of choroidal neovascularization in angioid streaks. Retina. 1997; 17:12-16.

5. Menchini U, Virgili G, Introini U, et al. Outcome of choroidal neovascularization in angioid streaks after photodynamic therapy. Retina. 2004;24:763-771.

6. Marco Zarbin. Should corticosteroids be considered as part of the standard care with photodynamic therapy? Am J Ophthalmol. 2006;124:563-571.

7. Spaide R, Sorenson J, Maranan L. Combined photodynamic therapy with verteporfin and intravitreal triamcinolone acetonide for choroidal neovascularization. Ophthalmology. 2003;110:1517-1525.

8. Ricci F, Cedrone C, Cerulli L. Standardized measurement of visual acuity. Ophthalmic Epidemiol. 1998;5:41-53.

9. Ciulla TA, Criswell MH, Danis RP, Hill TE. Intravitreal triamcinolone acetonide inhibits choroidal neovascularization in a laser-treated rat model. Arch Ophthalmol. 2001;119:399-404.

10. Gillies MC, Simpson JM, Luo W, et al. A randomized clinical trial of a single dose of intravitreal triamcinolone acetonide for neovascular age-related macular degeneration: one-year results. Arch Ophthalmol. 2003;121:667-673.

11. Spaide RF, Sorenson J, Maranan L. Photodynamic therapy with verteporfin combined with intravitreal injection of triamcinolone acetonide for choroidal neovascularization. Ophthalmology. 2005;112:301-304.

12. Arias L, Garcia-Arumi J, Ramon JM, et al. Photodynamic Therapy with Intravitreal Triamcinolone in Predominantly Classic Choroidal Neovascularization. One-Year Results of a Randomized. Study Ophthalmology. 2006;112:1227-1231.

13. Kaiser PK. Verteporfin. therapy in combination with triamcinolone: published studies investigating a potential synergistic effect. Curr Med Res Opin. 2005;21:705-713.

14. Sandowski T, Steinmeyer J. Effects of polysulfated glycosaminoglycan and triamcinolone acetonid on the production of proteinases and their inhibitors by IL-1alpha treated articular chondrocytes. Biochem Pharmacol. 2002;64:217-227.

15. Wang YS, Friedrichs U, Eicler W, et al. Inhibitory effects of triamcinolone acetonide on bFGF- induced migration and tube formation in choroidal microvascular endothelial cells. Graefes Arch Clin Exp Ophthalmol. 2002;240:42-48. 
16. Gordon SG, Overland JF, Foley J. Evidence for increased protease activity secreted from cultured fibroblasts from patients with pseudoxanthoma elasticum. Conn Tissue Res. 1978;6:61-68.

17. Schwartz E, Cruickshank FA, Lebwohl MG. Elastase-like protease and elastolytic activities expressed in cultured dermal fibroblasts derived from lesional skin of patients with pseudoxanthoma elasticum, actinic elastosis, and cutis laxa. Clin Chim Acta. 1988;176:219-224.

18. Quaglino D, Sartor L, Garbisa S, et al. Dermal fibroblasts from pseudoxanthoma elasticum patients have raised MMP-2 degradative potential. Biochim Biophys Acta. 2005;1741:42-47.

19. Ahmadieh H, Taei R, Soheilian M, Riazi-Esfahani M, Ahadi H. Single-session photodynamic therapy combined with intravitreal bevacizumab for neovascular age-related macular degeneration. Eur J Ophthalmol. 2008;18:297-300.

20. Teixeira A, Moraes N, Farah ME, Bonomo PP. Choroidal neovascularization treated with intravitreal injection of bevacizumab (Avastin) in angioid streaks. Acta Ophthalmol Scand. 2006; 84:835-836.
21. Rinaldi M, dell'Omo R, Romano M, et al. Intravitreal bevacizumab (Avastin) in choroidal neovascularization secondary to angioid streaks. Arch Ophthalmol. 2007;125:1422-1423.

22. Nishant S, Kavitha V, Vishali G, Ramandeep S, Amod G. Intravitreal bevacizumab (Avastin) in choroidal neovascular membrane in angioid streaks. Indian J Ophthalmol. 2007;55:457-458.

23. Lommatzch A, Spital G, Trieschmann M, Pauleikhoff D. Intraocular application of bevacizumab for the treatment of choroidal neovascularization secondary to angioid streaks. Ophthalmologe. 2007; 104:325-328.

24. Bhatnagar P, Freud BK, Spaide RF, et al. Intravitreal bevacizumab for the management of choroidal neovascularization in pseudoxanthoma elasticum. Retina. 2007;27:897-902.
Clinical Ophthalmology

\section{Publish your work in this journal}

Clinical Ophthalmology is an international, peer-reviewed journal covering all subspecialties within ophthalmology. Key topics include: Optometry; Visual science; Pharmacology and drug therapy in eye diseases; Basic Sciences; Primary and Secondary eye care; Patient Safety and Quality of Care Improvements. This journal is indexed on

\section{Dovepress}

PubMed Central and CAS, and is the official journal of The Society of Clinical Ophthalmology (SCO). The manuscript management system is completely online and includes a very quick and fair peer-review system, which is all easy to use. Visit http://www.dovepress.com/ testimonials.php to read real quotes from published authors. 